\title{
The 2001 Educational Policy and Accreditation Standards: Implications for MSW Programs
}

\author{
Marion Wagner \\ Paul Newcomb \\ Robert Weiler
}

\begin{abstract}
The 2001 Educational Policy and Accreditation Standards (EPAS) establish guidelines for baccalaureate and masters' level social work education throughout the United States. In this article, the authors discuss implications of the EPAS for masters' level social work educational programs. They focus especially upon the opportunities afforded programs to introduce innovative educational experiences.
\end{abstract}

Keywords: MSW education, social work, EPAS, educational policies, accreditation standards

$\mathrm{T}$

The Council on Social Work Education (CSWE) Educational Policy and Accreditation Standards (EPAS) (CSWE, 2001) offer challenges, opportunities, and increased flexibility to MSW Programs. As with all accreditation documents, implementation will bring clarification and a "legislative" history, providing further resources for MSW programs working to stay in compliance while adapting curricula and program design to the needs of a new century. To be implemented in July 2002, EPAS offers social work programs an opportunity to deliver social work education in a more flexible manner than in the recent past.

According to the CSWE bylaws, the statements on educational policy and the accompanying accreditation standards are subject to review every seven years. In past iterations, the policy statement and standards have been developed sequentially, with the policy statement developed by the Commission on Educational Policy and the standards written by the Commission on Accreditation. EPAS was a joint product of the commissions working in tandem with one another. The commissions hoped to reduce the size of the documents, streamline the accreditation process, and encourage educational innovation. EPAS represents amended views of the purpose of social work education, program structure, and the eight (formerly nine) essential curricula areas: values and ethics, diversity, populations-atrisk and social and economic justice, human behavior and the social environment (HBSE), social welfare policy and services, social work practice, research, and field education. Although the general content areas remain the same, social work pro-

Marion Wagner, Ph.D. is Associate Professor and Director of M.S.W. Education, Indiana University School of Social Work, Indianapolis Campus; Paul Newcomb, Ph.D. is Associate Professor and M.S.W. Program Director, Indiana University School of Social Work, South Bend Campus; and Robert Weiler, A.B.D. is Lecturer and Interim M.S.W. Program Director, Indiana University School of Social Work, Northwest campus.

Copyright@ 2001 Advances in Social Work Vol. 2 No. 2 (Fall 2001) 113-118.

Indiana University School of Social Work. 
grams may use the new policies and standards to present these curricular areas in innovative and creative combinations.

\section{PURPOSE OF SOCIAL WORK EDUCATION}

The purpose statement in the EPAS pushes students towards leadership in the profession. It reads as follows: "The purposes of social work education are to prepare competent and effective professionals, to develop social work knowledge, and to provide leadership in the development of service delivery systems" (CSWE, 2001, p. 5). Contrast that with the previous purpose statement, which read: "The purpose of professional social work education is to enable students to integrate the knowledge, values, and skills of the social work profession into competent practice" (CSWE, 1992, p. 3). The EPAS statement may reflect a growing recognition of requirements for social workers to participate in the building of the professional knowledge base and to take leadership roles in policy-making arenas. A message for MSW programs includes encouragement to expand beyond interpersonal direct practice foci. Programs will need to highlight the integral connection of research, policy, and practice in their curricula.

\section{CURRICULUM INTEGRATION: FOUNDATION AND CONCENTRATION}

With the new EPAS, MSW programs have an opportunity to develop foundation and concentration curriculum in a more integrated manner than was previously assumed. The eight curricular areas are to be presented in the foundation content and further developed in the concentration content. MSW programs are thus encouraged to consider combining curricular areas, providing for potentially seamless transitions through the curricular structure. MSW programs have heretofore presented HBSE, practice, policy, research, and field curricula in discrete blocks. While practice courses refer to HBSE content, policy classes discuss the need for and impact of research, and field content includes reference to the other areas, actual content has continued to be presented separately. In particular, HBSE courses are generally presented only as foundation content. Although faculty understand the connections and use foundation content as building blocks, students may not always see the connection between theories learned in the foundation content and content addressed in concentrations.

The clarity of the new EPAS in describing foundation and concentration content opens doors for programs to develop new concepts for combining area content in innovative ways. One innovative way is that courses may be developed that combine two or more content areas in the foundation, to better prepare students for the need to combine knowledge and skills in their practice. For example, a course could be developed for foundation students wherein they study basic theories, practice methods, policy development, and research methodologies essential for work with communities. The course could be delivered concurrently with a student's field placement in a community development agency. Integration of such content would reduce redundancy between and among courses and would free-up credit hours for specialized concentration content. Introducing creative combinations of course content in the concentration curricula would further enhance students' appreciation for the need to consider all content areas in their practice. Course content on values and ethics, diversity, populations-at-risk, and social justice is already 
generally integrated throughout the curriculum and would continue to serve as core subject matter in both foundation and concentration courses.

Creating a smoother curricular flow from foundation to concentration content and infusing the eight areas throughout the curriculum may also encourage programs to strengthen concentration content. Many MSW programs spend half the student credit hours presenting the foundation. With the new EPAS, a majority of credit hours may be spent presenting concentration content, with continuing integration of the eight areas.

\section{DIVERSITY, POPULATIONS-AT-RISK AND SOCIAL JUSTICE}

The new EPAS further advances the social work professional commitment to celebrate diversity and concern for populations-at-risk and social justice. The new policy is more specific about the need for cultural competence, which should encourage programs to focus even more on expanding content. The recently approved National Association of Social Workers (NASW) standards for cultural competence will assist programs in improving content on diversity (NASW, 2001).

Several challenges are included for social work educators who are committed to social justice for all populations-at-risk. For example, EPAS requires all programs to prepare their graduates to "Practice without discrimination and with respect, knowledge and skills related to clients' age, class, color, culture, disability, ethnicity, family structure, gender, marital status, national origin, race, religion, sex, and sexual orientation" (CSWE, 2001, p. 8). However, discussions of the foundation content addressed within the areas of diversity and populations-at-risk and social justice do not specifically list populations or categories of discrimination or oppression. The Curriculum Policy Statement (CPS) of 1992, replaced by the current EPAS, was more specific. For example, under the populations-at-risk category was the statement, "The curriculum must provide content about people of color, women, and gay and lesbian persons. Such content must emphasize the impact of discrimination, economic deprivation, and oppression upon these groups" (CSWE, 1992, p. 8). By including these groups in only the longer list, the new EPAS may inadvertently diminish the requirement for schools of social work to particularly support social and economic justice for these three categories and include specific content on each. Legal advice led CSWE to reduce examination of programs' commitment to social justice, especially for lesbian, gay, bisexual, or transgendered (LGBT) people, as civil rights protections for LGBT people are not currently federally mandated (Parr \& Jones, 1996). As a result, social work educators in academic environments who do not share social work's mission and philosophy of human rights have less accreditation policy support for non-discriminatory practices in their programs. Unfortunately, this may decrease opportunities for social work educators to model good practice for students in the area of diversity. The combination of this reduction and the deletion of specific population groups from the curricular areas may lead to less focused content on populations-at-risk and diversity. Programs may well defend the omission of one group by the inclusion of the others. Social work educators committed to the NASW Code of Ethics will need to be vigilant in maintaining quality content on all populations in the curriculum. In preparing graduates to practice "without discrimination and with respect, knowledge, and skills related to clients' ... family structure, gender, marital sta- 
tus... sex, and sexual orientation" (CSWE, 2001, p. 8) may encourage programs in all university contexts to expand social policy content by focusing on the need to secure federal civil rights for LGBT people.

\section{RESOURCE NEEDS}

What resources do MSW programs need to take advantage of potential opportunities inherent in the new EPAS? Programs with a core of faculty expertise in curriculum development and design may be better positioned to create innovative programs that improve educational quality. Programs need faculty and administrators who are sufficiently creative to think "outside of the box." Faculty, deans, and directors who actively participated in the formulation of the new standards should be important resources as should CSWE site visitors trained under the new standards. As this process is laborious, faculty motivation and the availability of time become important additional resources in relation to these tasks. In order for these resources to be appropriately harnessed, however, strong and innovative leadership is required at both the administrative level and the program level. Deans and MSW program directors need to work together in a cooperative manner, a goal which is easier to accomplish if they share a similar vision of the new curriculum models emerging from faculty discussions and processes.

\section{CHALLENGES AND OBSTACLES}

What challenges and potential obstacles face MSW programs in creating innovative curriculum designs? For at least four reasons, some faculty may resist new curriculum models. First, in terms of effort, it is simply easier to continue business as usual than to design and implement new ideas, regardless of how attractive they might seem. Second, faculty may be required to retool and develop new areas of expertise corresponding to emerging trends in practice and societal needs. Curriculum change provides an opportunity to make our teaching relevant for our students but requires us to stay abreast of such developments. This problem is exacerbated by the fact that many faculty members are quite removed from practice. The rapidly changing context of social work practice underscores this problem. Third, it is difficult to reach a consensus on innovative curriculum change, especially among larger MSW programs. The degree and extent of support for change is likely to vary greatly among faculty. Some faculty may vigorously oppose innovation, making implementation difficult, if not impossible. Fourth, some innovative teaching modalities (e.g., distance or on-line learning models) may be opposed by faculty on pedagogical grounds or because they require faculty to develop new skills and familiarity with technological advances in teaching and learning.

In the past, the Council on Social Work Education seemed to make it difficult for MSW programs to implement innovative curriculums that deviated from "the letter of the law" (i.e., accreditation policies and standards). Many programs were afraid to make significant changes that might place them at risk for losing accreditation. The historic difficulty that several programs had in implementing part-time programs is a case-in-point. As a consequence of the perceived risk, MSW programs may be reluctant to take full advantage of the new flexibility afforded by the new EPAS. Thus far, no programs have gone up for accreditation under the new standards. It is likely to take several years of experience with these processes before 
social work educators feel confident enough to move forward in curriculum innovation. Such curriculum changes also have a significant impact on schools of social work in relation to the practice community. It will be essential to involve practice community leaders and consumers of social services in this process, as their input is needed to develop relevant curriculum models for the $21^{\text {st }}$ century. Their participation is vital in both the curriculum development and implementation phases.

\section{SUMMARY AND CONCLUSIONS}

MSW social work programs are entering an exciting period of growth potential unprecedented in the history of social work education. While continuing to focus on content areas that remain relatively unchanged from the previous accreditation standards, schools of social work are now, under the new EPAS standards, capable of being more creative and innovative in developing their curricula. Programs will be in the best position to take advantage of the new standards if they remain open to new possibilities and if they encourage the imaginative process to unfold. They will be able to recreate and redefine themselves with a greater degree of latitude than perhaps they have enjoyed in the past.

The degree of flexibility that the new EPAS affords to MSW programs brings many challenges and opportunities. No substantial change in the life of an educational institution-whether positive or negative-comes without a shift in priorities, focus, and energy. As in many areas of human life, change does not always come easy. However, with the adequate resources outlined in this paper, what might be perceived as obstacles to growth can be reframed as positive challenges.

The eight areas of curricular content can now be more fully integrated throughout foundation and concentration coursework. This provides programs with opportunities to provide a more seamless and connected approach to content delivery. Content on research, policy, and practice, as well as values and ethics, diversity, populations-at-risk, and social justice, and the notion of cultural competence, is also integrated throughout the curriculum. MSW programs will need to ensure that categories of persons affected by discrimination or oppression continue to be identified and specified; that the MSW curriculum supports social and economic justice for these populations and includes specific, high-quality content regarding all at-risk-persons; and that social policy content expands to address the civil rights of these populations.

The 2001 EPAS permits program administrators, deans, and directors to encourage and support faculty in developing and implementing new educational approaches. Interestingly, under the new policies and standards, MSW programs that maintain the educational status quo may be at greater risk than those that engage in regular program assessment and make innovative changes based upon findings. The EPAS implicitly encourages programs and faculty to engage in the invigorating process of professional development, explore new arenas of academic interest and expertise while keeping abreast of emerging trends in social work practice. Faculty and staff alike can utilize their brainstorming, negotiation, and compromise skills while reaching consensus on comprehensive, innovative program change.

MSW programs can step forward with new confidence and optimism, taking advantage of the flexibility of the new EPAS in regenerating their curricula without 
fear of jeopardizing their accreditation. They can, with a greater degree of freedom, aspire to achieve their mission and reach their goals in ways and means that best match community and societal needs and their own contexts and resources. Under the new standards, excellence in social work education becomes a genuine possibility.

The good counsel of the social work practice community, consumers, and stakeholders can and should be sought throughout the process of curricula revision and implementation. Their participation ensures that curricula models are relevant for clients today and in the future.

The modified statement of the purpose of social work education, an integral component of the EPAS, steers the profession and our MSW graduates beyond a narrowly-focused approach to social work practice into the development of relevant and effective service delivery systems, the discovery of knowledge, and the formulation of social policy. We stand at a turning point in graduate social work education. We must prepare for-and we can ascend to - the challenge of becoming what our students, clients, and stakeholders need us to be. We believe that the 2001 EPAS provides just such an opportunity.

\section{References}

Council on Social Work Education. (1992). Curriculum policy statement for master's degree programs in social work education. Alexandria, VA: Author.

Council on Social Work Education. (2001). Educational policy and accreditation standards. Alexandria, VA: Author.

National Association of Social Workers. (2001). NASW standards of cultural competence in social work practice [Online]. Washington, DC: Author. Retrieved November 15, 2001, from the World Wide Web: http://www.socialworkers.org/pubs/standards/cultural.htm.

Parr, R. G., \& Jones, L. E. (1996). Point/Counterpoint: Should CSWE allow social work programs in religious institutions an exemption from the accreditation nondiscrimination standard related to sexual orientation? Journal of Social Work Education, 32, 297-313.

\section{Author's Note:}

Address correspondence to: Marion Wagner, Ph.D., Indiana University School of Social Work, 902 West New York Street, Indianapolis, IN 46202-5156 USA, iboh100@iupui.edu. 